\title{
Vacina da varicela na infância
}

Ana Garrido, ${ }^{*}$ Clara Pinto Ferreira**

Objectivos: Rever a evidência disponível sobre a vacinação contra a varicela em crianças saudáveis, avaliando a sua efectividade e segurança.

Fontes de Dados: Base de dados MEDLINE e sítios na internet de medicina baseada na evidência.

Métodos de revisão: Pesquisa de Normas de Orientação Clínica, revisões sistemáticas, meta-análises e artigos originais publicados entre Janeiro de 2005 e Novembro de 2009, em inglês, português e espanhol, utilizando os termos MeSH chickenpox vaccine, infant, child preschool e child. Para atribuir o nível de evidência e a força de recomendação foi utilizada a escala Strength of Recommendation Taxonomy (SORT) da American Family Physician.

Resultados: Foram encontrados 14 estudos que avaliaram a efectividade vacinal: 5 normas de orientação clínica (2 com força de recomendação A), 3 revisões sistemáticas (2 com nível de evidência 1), 1 meta-análise (nível de evidência 1), 1 caso-controlo e 4 coortes. Verificou-se que a vacina apresenta uma efectividade de 70 a $90 \%$ na prevenção de qualquer forma de varicela e de 95 a 100\% na prevenção de doença moderada a grave, num período não superior a dez anos. O esquema de duas doses mostrou maior efectividade a longo prazo que o esquema de dose única. Dois estudos que avaliaram a segurança vacinal concluíram que a vacina é segura e bem tolerada (1 ensaio clínico aleatorizado e controlado com nível de evidência 1).

Conclusões: Considerando a evidência disponível, pode concluir-se que a vacina da varicela é uma intervenção efectiva e segura em crianças saudáveis (Força de Recomendação A). No entanto, a sua implementação deverá ser universal, de forma a permitir uma taxa de cobertura elevada, podendo considerar-se a possibilidade de duas doses.

Palavras-Chave: Vacina Contra a Varicela; Lactente; Criança Pré-escolar; Criança.

\section{INTRODUÇÃO}

A varicela é uma infecção altamente contagiosa, causada pelo vírus varicela-zoster (VVZ) e caracteriza-se por um exantema pápulo-vesicular pruriginoso. ${ }^{1}$ Segundo dados norte-americanos anteriores à introdução da vacina, mais de 90\% dos casos ocorriam antes dos 15 anos de idade, com maior incidência entre os 5 e os 9 anos. ${ }^{2}$ Na maioria das crianças a varicela evolui de forma benigna e auto-limitada, mas pode apresentar complicações graves, nomeadamente sobre-infecção bacteriana cutânea, complicações neurológicas (ataxia cerebelosa, encefalite, meningite), respiratórias (pneumonia), hematológicas (púrpura trombocitopénica), gastrointestinais, entre outras. ${ }^{3}$

Após a infecção, o VVZ fica em latência, podendo reactivar em 10 a $30 \%$ dos indivíduos sob a forma de herpes-zoster. Esta infecção pode evoluir com complicações semelhantes às da varicela e, em grupos de ris-

*Interna de Medicina Geral e Familiar - USF Lidador (ACES Maia)

**Interna de Medicina Geral e Familiar - USF Horizonte (ULS Matosinhos) co (idosos e imunodeprimidos), está associada a morbi-mortalidade significativa. ${ }^{4}$

Dados portugueses referentes ao ano de 2007 apontam uma taxa de incidência de varicela de 649,7 casos por 100.000 indivíduos na população geral. Esta taxa é superior nos grupos etários dos 0 aos 4 anos (6.241,5 por 100.000) e dos 5 aos 9 anos (3.536,2 por 100.000). ${ }^{4}$

A vacina contra a varicela é uma vacina de vírus vivo atenuado (estirpe $O k a$ ) desenvolvida no Japão em 1970. Foi aprovada nos Estados Unidos da América (EUA) em 1995 e está recomendada para vacinação universal. Vários países europeus (Alemanha, Espanha, Itália, Holanda e Suíça) também adoptaram a vacinação universal contra a varicela. ${ }^{4}$ Nestes países, a implementação universal da vacina demonstrou ser uma estratégia eficaz na redução do número de casos, internamentos, consultas médicas e mortes. ${ }^{5}$

Em Portugal, a vacina foi introduzida em 2003, mas não está incluída no Plano Nacional de Vacinação (PNV), pelo que a decisão de a prescrever individualmente deve ser fundamentada. Por um lado, mesmo sendo uma doença habitualmente benigna, a sua elevada frequência entre a comunidade infantil condicio- 
na custos consideráveis, devido ao absentismo escolar e consequente absentismo laboral parental. Por outro, a efectividade e duração da imunidade conferida pela vacina têm sido alvo de inúmeros estudos, muitos deles em situações de surtos em comunidades escolares, em crianças previamente vacinadas. ${ }^{4}$ Questiona-se também o impacto a longo prazo da vacinação contra a varicela na incidência de herpes zoster. ${ }^{2}$

Este artigo tem por objectivo rever a evidência disponível sobre a vacinação contra a varicela em crianças saudáveis, avaliando a sua efectividade e segurança.

\section{MÉTODOS}

Foi realizada uma pesquisa sistemática nas bases de dados Medline, National Guideline Clearinghouse, Cochrane Library, DARE, Bandolier, TRIP Database, Canadian Medical Association e Índex de Revistas Médicas Portuguesas (RMP) de Normas de Orientação Clínica (NOC), revisões sistemáticas (RS), meta-análises (MA) e artigos originais, publicados entre Janeiro de 2005 e Novembro de 2009, em inglês, português e espanhol. Foram utilizando os termos MeSH chickenpox vaccine, infant, child preschool e child para a pesquisa na MEDLINE e sítios na internet de medicina baseada na evidência; para pesquisa no Índex RMP foram usadas as palavras-chave «vacina da varicela» $\mathrm{e}$ «infância».

Foram definidos os seguintes critérios de inclusão: a) População: crianças saudáveis (de 1 a 12 anos); b) Intervenção: vacina da varicela; c) Comparação: ausência de vacinação ou placebo; Outcome: efectividade (diminuição da incidência, gravidade e morbi-mortalidade) e segurança (incidência de efeitos adversos). Foram excluídas do estudo crianças com diagnóstico prévio de varicela.

Para atribuir o nível de evidência e a força de recomendação foi utilizada a escala Strength of Recommendation Taxonomy (SORT) da American Family Physician. ${ }^{6}$

No sentido de facilitar a compreensão dos resultados apresenta-se uma breve definição de alguns conceitos:

- Gravidade da varicela: não há uma definição consensual, mas a maioria dos estudos define a gravidade com base no número de lesões e na incidência de complicações ou necessidade de hospitalização. Define-se então varicela ligeira na presença de menos de 50 lesões; moderada entre 50 e 500 lesões; grave se mais de 500 lesões, complicações ou hospitalização. ${ }^{7}$

- Varicela vacinal: exantema pápulo-vesicular associado à vacinação. A etiologia (estirpe selvagem / estirpe vacinal) está provavelmente relacionada com o tempo decorrido após a vacinação: erupções que ocorrem nas primeiras duas semanas estão relacionadas com a estirpe selvagem; erupções nos 15 a 42 dias seguintes estão associadas à estirpe vacinal. ${ }^{3}$

- Breakthrough varicella: infecção em indivíduos vacinados há mais de 42 dias, após exposição à estirpe selvagem. Pode ocorrer por falta de resposta à vacina ou diminuição da imunidade ao longo do tempo. ${ }^{3,7}$

\section{RESULTADOS}

Da pesquisa inicial obtiveram-se 310 artigos, tendo-se excluído os artigos que não cumpriam os objectivos ou os critérios de inclusão, os artigos repetidos e os estudos originais que foram alvo de análise nas NOC, MA e RS incluídas nesta revisão. Foram seleccionados dezasseis artigos: cinco NOC, ${ }^{1,4,8,9,10}$ três Revisões Sistemáticas, ${ }^{2,7,11}$ uma Meta-análise ${ }^{12}$ e sete Estudos Originais. ${ }^{13-19}$

Nos EUA, o Advisory Committee on Immunization Practices (ACIP) do Centers for Disease Control and Prevention (CDC) recomenda a vacinação de crianças entre os 12 meses e os 12 anos, com 2 doses (a primeira entre os 12 e os 15 meses, a segunda entre os 4 e os 6 anos). O esquema de uma dose vacinal vigorou até 2006, apresentando uma efectividade entre os 70 e os 90\% (Quadro I). Contudo, a ocorrência de breakthrough varicella, de surtos de varicela em escolas com elevada cobertura vacinal e a alteração do pico de incidência de varicela dos 3 aos 6 anos na fase pré-vacinal para os 9 aos 11 anos na fase pós-vacinal, levaram o ACIP a recomendar, em 2006, a introdução de uma segunda dose, dos 4 aos 6 anos. A taxa de efeitos adversos registada após comercialização foi de 52,7 casos por 100.000 doses distribuídas. Os mais frequentemente reportados foram exantema, febre e reacções no local da injecção. Registaram-se ainda raras complicações graves como pneumonia, hepatite e varicela disseminada, mas que ocorreram em imunodeprimidos ou doentes com patologia crónicas. $^{8}$

A American Academy of Pediatrics, numa NOC baseada na evidência, subscreve as recomendações do 


\begin{tabular}{|c|c|c|}
\hline Referência & Recomendação & $\begin{array}{c}\text { Força de } \\
\text { Recomendação }\end{array}$ \\
\hline $\begin{array}{l}\text { ACIP, } 2007^{8} \text { e American } \\
\text { Academy of Pediatrics, } \\
2007^{9}\end{array}$ & 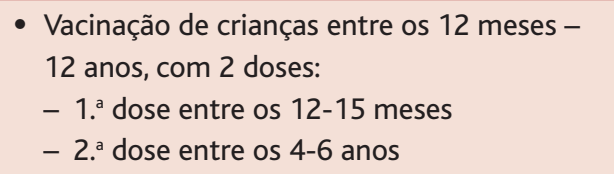 & A \\
\hline $\begin{array}{l}\text { Canadian Paediatric } \\
\text { Society, } 2005^{1}\end{array}$ & $\begin{array}{l}\text { - Vacinação universal de crianças a partir dos } \\
12 \text { meses de idade (sem história prévia de } \\
\text { doença), com } 1 \text { dose }\end{array}$ & C \\
\hline $\begin{array}{l}\text { Australian } \\
\text { Immunization } \\
\text { Handbook, } 2008^{10}\end{array}$ & $\begin{array}{l}\text { - } 1 \text { dose aos } 18 \text { meses (PNV) } \\
\text { - 2. dose recomendada, mas não incluída no } \\
\text { PNV }\end{array}$ & $C$ \\
\hline $\begin{array}{l}\text { Sociedade Portuguesa } \\
\text { de Pediatria, } 2009^{4}\end{array}$ & $\begin{array}{l}\text { - Crianças: vacinar só após introdução no PNV } \\
\text { - } 2 \text { doses }\end{array}$ & C \\
\hline
\end{tabular}

ACIP - Advisory Committee on Immunization Practices

PNV - Plano Nacional de Vacinação

ACIP no que respeita à recomendação de duas doses vacinais a crianças entre os 12 meses e os 12 anos (com o intervalo de, pelo menos, 3 meses), atribuindo-lhe uma força de recomendação A. A primeira dose está recomendada entre os 12 e os 15 meses (força de recomendação A), excepto se houver evidência de imunidade ao VVZ (vacinação prévia, imunidade confirmada laboratorialmente, varicela ou herpes zoster diagnosticada por profissional de saúde) ou contra-indicação para vacinação; a segunda dose está recomendada entre os 4 e os 6 anos (força de recomendação $\mathrm{C}$, devido à menor evidência sobre o intervalo de tempo entre as duas doses). Em termos de segurança, estudos concluíram que a vacina é segura e bem tolerada, sendo dor e rubor no local de inoculação os efeitos adversos mais frequentes. Nos casos de breakthrough varicella verifica-se co-infecção de duas estirpes (vacinal e selvagem) de VVZ, o que poderá aumentar o risco de herpes zoster na idade adulta, por reactivação da estirpe selvagem, comparativamente a vacinados que não tiveram breakthrough varicella. ${ }^{9}$

A Canadian Paediatric Society recomenda a vacinação universal em dose única, com início aos 12 meses de idade, bem como a vacinação de crianças não imunes (esquema de vacinação em atraso) e dos contactos domiciliares de crianças não imunes com alto risco de doença grave. Os programas de vacinação canadiana estão a ser monitorizados, bem como a epidemiologia do VVZ, para determinar a necessidade de introduzir, no futuro, um esquema de duas doses. ${ }^{1}$

O programa de imunização australiano recomenda a administração de uma dose aos 18 meses de idade. A administração de uma segunda dose está recomendada, pois aumenta a protecção e diminui o risco de breakthrough varicella, no entanto não está incluída no PNV australiano. ${ }^{10}$

Em Portugal, segundo a Sociedade Portuguesa de Pediatria, a vacinação contra a varicela só deverá ser considerada se a vacina for incluída no PNV. Em caso de vacinação, deverão ser administradas 2 doses, entre os 12 meses e os 12 anos, com um intervalo mínimo de 3 meses. ${ }^{4}$

Três revisões sistemáticas ${ }^{2,7,11}$ publicadas em $2007 \mathrm{e}$ 2008, com o objectivo de verificar a efectividade da vacina da varicela, estão resumidas no Quadro II.

Marin et al analisaram 41 estudos publicados nos EUA e concluíram que uma dose vacinal apresenta uma efectividade de 80 a $85 \%$ na prevenção de varicela de qualquer gravidade e superior a $95 \%$ na prevenção de formas graves. O programa vacinal americano reduziu a incidência de varicela em 57 a 90\%, as hospitalizações em 75 a $88 \%$ e as mortes em mais de $66 \%$. O maior declínio na incidência verificou-se em crianças com menos de 10 anos, mas verificou-se uma alteração no pico de incidência (3-6 anos em 1995 para 9-11 anos em 2005), com aumento da idade média à data da doença, quer para as crianças vacinadas, quer para as não vacinadas. A ocorrência de surtos, mesmo em populações escolares com elevada cobertura vacinal, alertou para o facto de uma dose ser insuficiente para gerar imunidade de grupo e prevenir a transmissão do vírus selvagem entre vacinados. Um ensaio clínico que comparou uma e duas doses concluiu que as crianças que rece- 


\begin{tabular}{|c|c|c|c|c|c|}
\hline Referência & N. ${ }^{\circ}$ de estudos & Intervenção & Resultados & Comentários & $\begin{array}{l}\text { Nível de } \\
\text { Evidência }\end{array}$ \\
\hline $\begin{array}{l}\text { Marin et al, } \\
2008^{2}\end{array}$ & $\begin{array}{l}41 \text { (maioria } \\
\text { observacionais) }\end{array}$ & 1 ou 2 doses & $\begin{array}{l}\text { - } 1 \text { dose - efectividade } \\
\text { de } 85 \% \\
\text { - } 2 \text { doses - Maior } \\
\text { efectividade (98,3\%) e } \\
\text { menor risco de } \\
\text { breakthrough varicella } \\
\text { - Segura (raros efeitos } \\
\text { adversos) }\end{array}$ & - Surtos em vacinados & 2 \\
\hline $\begin{array}{l}\text { Seward et al, } \\
2008^{7}\end{array}$ & $\begin{array}{l}17 \text { ( } 2 \text { caso-controlo, } \\
1 \text { observacional de } \\
\text { contactos de casos, } \\
13 \text { coortes retrospectivas; } \\
1 \text { coorte prospectiva) }\end{array}$ & 1 dose & $\begin{array}{l}\text { - } 80-85 \% \text { efectividade na } \\
\text { prevenção qualquer } \\
\text { forma de varicela } \\
\text { - } 97-100 \% \text { efectividade } \\
\text { prevenção varicela grave }\end{array}$ & $\begin{array}{l}\text { - Excelente protecção, mas } \\
\text { é necessário maior taxa } \\
\text { de efectividade para } \\
\text { prevenir os surtos }\end{array}$ & 1 \\
\hline $\begin{array}{l}\text { Swingler, } \\
2007^{11}\end{array}$ & 2 (1 RS e 1 ECAC) & 1 dose & $\begin{array}{l}\text { - Redução da incidência } \\
\text { aos } 2 \text { anos pós-vacina } \\
\text { - Diminuição da gravidade } \\
\text { da doença }\end{array}$ & $\begin{array}{l}\text { - Sem efeitos adversos } \\
\text { significativos }\end{array}$ & 1 \\
\hline
\end{tabular}

RS - revisão sistemática

ECAC - ensaio clínico aleatorizado controlado

beram duas doses desenvolviam mais anticorpos e tinham um risco 3,3 vezes inferior de breakthrough varicella. Tendo em conta a incidência de varicela em crianças não vacinadas, a efectividade vacinal aumentou significativamente após 2 doses (98,3\% [IC a 95\%: $97,3 \%$ - 99,0\%] vs 94,4\% [IC a 95\%: 92,9\% - 95,7\%]; $p<$ 0,001 ), num período observacional de 10 anos. ${ }^{2}$ Em termos de segurança a vacina apresenta um excelente perfil, com efeitos adversos graves pouco frequentes (5\% do total de notificações). Os efeitos adversos mais frequentes (dois terços das notificações) foram exantema, febre e reacção local. ${ }^{2}$

Seward et al incluíram 17 estudos numa revisão sobre efectividade vacinal e concluíram que, apesar de uma dose conferir excelente protecção (efectividade de 80 a $85 \%$ na prevenção de qualquer forma de varicela e de 97 a 100\% na prevenção de varicela grave), é necessária uma maior taxa de efectividade para interromper a transmissão e prevenir surtos. A efectividade é inferior à eficácia estimada (98\% após 2 anos de follow-up) descrita num ensaio clínico randomizado pré-introdução da vacina. Esta RS incluiu também dois estudos observacionais de efectividade pós-exposição (52 crianças sem história prévia de varicela ou vacinação, expostas a casos de varicela e posteriormente vacinadas num período inferior a três dias), concluindo uma efectividade de 42 a $95 \%$ na prevenção de varicela e de $100 \%$ na prevenção de formas graves de varicela. ${ }^{7}$

Em 2007, Swingler publicou uma RS de boa qualidade metodológica que analisou um ensaio clínico aleatorizado e controlado (ECAC) e uma RS (com outros dois ECAC), num total de 1283 crianças, tendo concluído uma efectividade global elevada. No ECAC incluído nesta revisão, não se verificaram diferenças significativas na incidência de varicela, embora o grupo placebo tenha apresentado maior risco de doença moderada a grave (RR 8,00 [IC a 95\%: 1,21-51,51]). No primeiro dos ECAC incluídos na RS verificou-se uma efectividade de $100 \%$ aos 24 meses pós-vacina, sendo que no segundo esta efectividade foi de $97 \%$ aos 29 meses pós-vacina. ${ }^{11}$ 


QUADRO III. Meta-análise
\begin{tabular}{l|l|l|l|l|l|} 
Referência & $\mathbf{N} .^{\circ}$ de estudos & N & Intervenção & \multicolumn{1}{c|}{ Resultados } & Nível de Evidência \\
\hline $\begin{array}{l}\text { Bayer et al, } \\
2007^{12}\end{array}$ & 14 (coortes) & 3.157 crianças & 1 dose & $\begin{array}{l}\text { - Efectividade limitada }(72,5 \%) \\
\text { Efectividade independente da cobertura } \\
\text { vacinal }\end{array}$ & 1 \\
\hline
\end{tabular}

Relativamente aos efeitos adversos, a RS verificou a existência de lesões máculo-papulares maiores no grupo vacinal, embora esta diferença não fosse estatisticamente significativa. Não foram reportados efeitos adversos no ECAC. ${ }^{11}$

Uma meta-análise publicada em 2007, com base em 14 estudos observacionais (total de 3.157 crianças) de surtos em escolas primárias ou ATL (Actividades de Tempos Livres) publicados entre 1995 e 2006, confirmou a efectividade limitada de uma dose da vacina (Quadro III). De facto, a efectividade vacinal variou consideravelmente (20 a 100\%) entre os estudos, tendo-se calculado uma efectividade global de 72,5\%. Nove dos estudos avaliaram a diminuição da imunidade: dois estudos não encontraram relação entre o tempo vacinal e diminuição da imunidade, mas não especificaram como chegaram a essa conclusão; 7 estudos verificaram, através do risco relativo, que quanto maior o tempo pós-imunização, maior a probabilidade de ocorrer breakthrough varicella em crianças previamente vacinadas. $^{12}$

Foram incluídos sete estudos originais nesta revisão, ${ }^{13-19}$ que se encontram resumidos no Quadro IV. Em 2005, Sheffer et al publicaram um estudo caso-controlo, cujo objectivo era determinar a efectividade da vacina em crianças israelitas com idades compreendidas entre 1 e 5 anos. Os casos foram notificados ao departamento de saúde do distrito de Telavive pelos médicos assistentes das crianças. Os pais destas foram posteriormente entrevistados telefonicamente, solicitando a avaliação subjectiva da gravidade da varicela (muito ligeira, ligeira, moderada e grave) e com questões relativas à data de início da varicela, sintomas, duração do exantema, dias de escola perdidos, possíveis contactos e história vacinal contra a varicela. De forma a evitar viéses de memória foram excluídos os casos em que a varicela havia ocorrido há mais de 6 semanas. Foram também excluídos os casos cuja vacinação ocorreu nas 6 semanas anteriores à doença, pela possibilidade de varicela vacinal. Participaram 151 casos de varicela e 298 controlos (crianças sem história de varicela), com taxas de vacinação de $6,6 \%$ nos casos e $38,3 \%$ nos controlos. A média de idades foi semelhante nos dois grupos. Verificou-se que nos vacinados a varicela apresentou uma evolução clínica mais suave (medida por percepção parental, presença de febre, tempo de cicatrização das lesões e dias de escola perdidos), com menor necessidade de tratamento antivírico ou antibiótico. Confirmou-se uma efectividade vacinal elevada (88\% para varicela de qualquer gravidade e $100 \%$ para doença moderada/grave). No entanto, este estudo documenta apenas a efectividade a curto prazo, uma vez que as crianças haviam sido vacinadas nos três anos anteriores. Mais ainda, nos vacinados a varicela pode ter sido tão branda que passou despercebida, não tendo sido diagnosticada e contribuindo para um falso aumento da taxa de efectividade. ${ }^{13}$

Staat et al realizaram um estudo retrospectivo entre 1996 e 2003, comparando as hospitalizações e atendimentos no SU de indivíduos com menos de 20 anos no período pré (1990-1995) e pós-introdução da vacina no PNV americano (1996-2003). Durante os 14 anos do estudo foram avaliados 4.168 casos de varicela: 335 crianças foram hospitalizadas e 3.833 tratadas no SU. Comparando os períodos pré e pós-introdução da vacina, a taxa de internamento por varicela diminuiu de 15,7 para 5,5 casos / 100.000 e a taxa de recurso ao SU diminuiu de 178,2 para 61,2 casos/ 100.000 . Os autores referem que esta diminuição pode ser devida não só à introdução da vacina, mas também ao melhor acesso aos cuidados de saúde primários e prescrição mais precoce do aciclovir (que poderá modificar o curso e impac- 


\begin{tabular}{|c|c|c|c|c|}
\hline Referência & $\mathbf{n}$ & Resultados & Comentários & Nível de Evidência \\
\hline $\begin{array}{l}\text { Sheffer et al, } \\
2005^{13}\end{array}$ & $\begin{array}{l}151 \text { Casos } \\
298 \text { Controlos }\end{array}$ & $\begin{array}{l}\text { - Taxa vacinação: } \\
\text { - Casos: } 6,6 \% \\
\text { - Controlos: } 38,3 \% \\
\text { - Varicela nos vacinados é mais leve } \\
\text { - Efectividade: } 88 \%\end{array}$ & $\begin{array}{l}\text { - Estudo de eficácia a curto prazo } \\
\text { (3 anos) } \\
\text { - Nos vacinados a doença pode } \\
\text { passar despercebida }\end{array}$ & 2 \\
\hline $\begin{array}{l}\text { Staat et al, } \\
2006^{14}\end{array}$ & 4.168 & $\begin{array}{l}\text { - Período pós-vacinal: < taxa de } \\
\text { internamentos e SU }\end{array}$ & $\begin{array}{l}\text { - Média de idades semelhantes no } \\
\text { período pré e pós-vacinal }\end{array}$ & 2 \\
\hline $\begin{array}{l}\text { Lee LE et al, } \\
2007^{15}\end{array}$ & 1.327 & $\begin{array}{l}\text { - Cobertura vacinal: } 63 \% \\
\text { - Efectividade: } 81 \% \text { (calculada em } \\
710 \text { crianças) } \\
\text { - Taxa de breakthrough varicella: } \\
11,2 \%\end{array}$ & $\begin{array}{l}\text { - Follow-up } 89 \% \\
\text { - Varicela mais grave e maior duração } \\
\text { do exantema nos não vacinados } \\
\text { - Dois casos de complicações } \\
\text { (conjuntivite e infecção bacteriana) }\end{array}$ & 2 \\
\hline $\begin{array}{l}\text { Giammanco } \\
\text { et al, } 2009^{16}\end{array}$ & $\begin{array}{l}28.188 \\
(0-14 \text { anos) } \\
2005-2007\end{array}$ & $\begin{array}{l}\text { - Cobertura vacinal: em 2007: } \\
\text { 70\% (12-23 meses); } 12,1 \% \\
\text { (11-12anos) } \\
\text { - Redução da taxa de incidência } \\
\text { anual de 95,7/1.000 (em 2004) } \\
\text { para 9/1.000 (em 2007) }\end{array}$ & $\begin{array}{l}\text { - } 22 \text { casos de breakthrough varicella } \\
\text { - } 7 \text { casos de herpes zoster }\end{array}$ & 2 \\
\hline $\begin{array}{l}\text { Kupek et al, } \\
2009^{17}\end{array}$ & 135.311 & $\begin{array}{l}\text { - Cobertura vacinal: } 72 \% \text { (idade } \\
\text { < } 5 \text { anos) e } 91 \% \text { (5-6 anos) } \\
\text { - Efectividade: } 37,75 \% \text { ( } 1-4 \text { anos) }\end{array}$ & $\begin{array}{l}\text { Diferença estatisticamente } \\
\text { significativa apenas no grupo etário } \\
1-4 \text { anos }\end{array}$ & 2 \\
\hline $\begin{array}{l}\text { Chaves et al, } \\
2008^{18}\end{array}$ & Não referido & $\begin{array}{l}\text { - } 25.306 \text { efeitos adversos } \\
\text { - } 5 \% \text { graves } \\
\text { - Excelente perfil de segurança }\end{array}$ & $\begin{array}{l}\text { Efeitos adversos reportados de } 1995 \\
\text { a } 2005\end{array}$ & 2 \\
\hline $\begin{array}{l}\text { Ferrera, } \\
2009^{19}\end{array}$ & $\begin{array}{l}507 \\
\text { (Crianças } \\
12-15 \text { meses) }\end{array}$ & $\begin{array}{l}\text { - } 47,7 \% \text { de efeitos adversos } \\
\text { relacionados com a vacina } \\
\text { - } 4 \text { efeitos adversos graves } \\
\text { - Vacina segura }\end{array}$ & $\begin{array}{l}\text { - Maioria das reacções de pequena } \\
\text { ou média intensidade }\end{array}$ & 1 \\
\hline
\end{tabular}

to da doença). Entre os dois períodos, não se verificou uma diferença significativa na média de idades das crianças, nem na média de dias de internamento $(4,3$ vs 3,9 dias no período pré e pós-vacinal, $p=0,50$ ). Identificou-se ainda a raça negra como um possível factor de risco para idas ao SU, por se ter verificado maior afluência ao SU de crianças negras com varicela no período pré e pós-introdução da vacina, embora em menor número neste último. ${ }^{14}$

Lee e seus colaboradores, num estudo retrospectivo referente ao ano lectivo 2002/2003, incluíram 1.134 crianças vacinadas, dos 5 aos 10 anos, expostas a casos de varicela na turma. Perante um aluno ausente por varicela, enfermeiras de saúde escolar avaliaram os registos médicos e escolares para verificação do estado vacinal. Posteriormente os pais destas crianças foram questionados relativamente a dados sobre a doença (data de início dos sintomas, uso de medicação, grau de gravidade, necessidade de atendimento médico, hospitalizações ou complicações). O diagnóstico foi confirmado por profissionais de saúde (médicos, enfermeiros ou técnicos de saúde pública). Obteve-se uma 
taxa global de cobertura vacinal de $63 \%$ (719 vacinados em 1.134 crianças), uma taxa de breakthrough varicella de $11,2 \%$ e uma taxa de efectividade de $81 \%$ (para uma população de 710 crianças sem varicela prévia), definida como redução da incidência de varicela entre as crianças vacinadas. Um estudo observacional nos anos lectivos 2002 a 2007 verificou que os casos de varicela em não vacinados apresentam maior gravidade (maior probabilidade de exantema generalizado, febre e outros sintomas constitucionais) e uma duração superior do exantema (média de dois dias) comparativamente aos vacinados (breakthrough varicella). Foram registados dois casos de complicações: conjuntivite numa criança não vacinada e infecção bacteriana da pele numa criança vacinada. ${ }^{15}$

Em 2009 foi publicado um estudo italiano, implementado entre 2005 e 2007 na região da Sicília, cujo governo autónomo introduziu a vacina no plano preventivo em 2003. Esta coorte incluiu 28.188 crianças dos zero aos 14 anos, tendo sido administrada uma dose vacinal às crianças no segundo ano de vida e aos adolescentes entre os 12 e os 13 anos. Para o cálculo da incidência de varicela foram consideradas 21.558 crianças; esta diminuiu de 95,7/1.000 crianças/ano em 2004 para 9/1.000 crianças/ano em 2007, redução verificada em todos os grupos etários. ${ }^{16}$

Um estudo observacional publicado em 2009 avaliou o impacto da vacinação contra a varicela numa cidade brasileira por um período de 11 anos (5 anos antes e 6 anos após introdução da vacina), comparativamente à incidência no restante estado (ausência de vacina), para quatro grupos etários (< 1, 1-4, 5-9 e 10-14 anos). Comparando o período pré e pós-vacinal verificou-se uma redução da incidência de 75,5\% para o grupo etário 1-4 anos; nos restantes grupos não se verificou uma redução estatisticamente significativa. A efectividade estimada da vacina para este grupo etário foi de $37,75 \% .{ }^{17}$

Dois estudos originais sobre segurança da vacina concluíram que esta é segura. Um estudo observacional analisou os efeitos adversos reportados de 1995 a 2005 , nos EUA. Os mais frequentes foram exantema, febre, reacção no local da injecção e urticária. A maioria ocorreu em crianças dos 12-23 meses que haviam recebido a vacina da varicela em simultâneo com outras vacinas. Dos 25.306 efeitos adversos (52,7/100.000 doses distribuídas), $5 \%$ foram classificados como graves (herpes zoster oftálmico, pneumonia, encefalite, trombocitopenia, vasculite e hepatite), sendo que a maioria ocorreu em crianças com co-morbilidade prévia. Ao longo dos 10 anos de estudo verificou-se um declínio na taxa de efeitos adversos graves. Foram reportadas algumas mortes após a vacinação, no entanto, não foi provada uma associação consistente. O estudo concluiu que a vacina tem um excelente perfil de segurança, com raros efeitos adversos graves, pelo que os benefícios conferidos compensam os potenciais riscos. ${ }^{18}$

Um ensaio clínico aleatorizado, controlado e duplamente cego realizado em França e Itália, publicado em 2009, avaliou a segurança de uma das vacinas da varicela comercializadas, comparativamente à da VASPR (utilizada como referência, pois o seu perfil de segurança é bem conhecido), em 507 crianças entre os $12 \mathrm{e}$ os 15 meses. Nos 42 dias seguintes à injecção foram registados (pelos pais) os efeitos adversos. Após vacinação, $47,7 \%$ das crianças apresentou pelo menos um efeito adverso relacionado com a vacina e $17,2 \%$ apresentou reacção no local da injecção. A maioria das reacções foi de pequena ou média intensidade. Foram reportados $65,1 \%$ de efeitos adversos sistémicos, a maioria dos quais sem relação com a vacina; febre foi o efeito adverso sistémico mais frequente $(25,3 \%)$, tendo-se verificado relação com a vacina. Exantema ou varicela vacinal foi registado em 3,2\% dos casos. Foram reportados quatro efeitos adversos graves: púrpura trombocitopénica idiopática, gastroenterite, pneumonia e laringospasmo. Este estudo concluiu que a vacina em causa é segura e apresenta um bom perfil de tolerabilidade em crianças dos 12-15 meses. ${ }^{19}$

\section{CONCLUSÕES}

Considerando a evidência disponível, pode concluirse que a vacina da varicela é uma intervenção efectiva e segura em crianças saudáveis (Força de Recomendação A), não só pela diminuição da incidência mas também da morbi-mortalidade associada. No entanto, a sua implementação deverá ser universal, de forma a permitir uma taxa de cobertura elevada, podendo considerar-se a possibilidade de duas doses.

Nos estudos incluídos verificaram-se algumas limitações, nomeadamente a variação na confirmação diagnóstica de varicela (médico, enfermeira, técnico de saúde pública ou informação parental) e na classifica- 
ção da gravidade da doença. A maioria dos estudos encontrados foram coortes realizados nos EUA e em contexto de surtos escolares, o que levanta a preocupação sobre potenciais viéses de selecção. De facto, há poucos estudos de efectividade realizados na Europa e os que existem são apenas estudos observacionais de incidência e morbi-mortalidade. Há poucos estudos caso-controlo duplamente cegos e os períodos de follow-up são curtos, o que limita as conclusões a longo prazo. Acresce ainda o facto de a maioria dos estudos abordar apenas o esquema de dose única, limitando as conclusões para o esquema de duas doses.

A utilização da vacina da varicela em Portugal é controversa, uma vez que, não fazendo parte do $\mathrm{PNV}$, a sua prescrição individual não permite atingir uma taxa de cobertura elevada. A vacinação em massa das crianças norte-americanas reduziu significativamente o número de casos, consultas médicas, internamentos e mortes por varicela nos EUA. Contudo, vários estudos questionaram a efectividade da vacina, pelo aparecimento de surtos em escolas norte-americanas com boa cobertura vacinal (levantando a hipótese de que uma dose não produz imunidade populacional suficiente para prevenir a transmissão na comunidade). A maior resposta imunitária e efectividade que se obtêm após uma segunda dose levou, em 2006, o ACIP a recomendar um esquema com duas doses. ${ }^{8}$

Um aspecto a ter em conta é a possível diminuição progressiva da imunidade conferida pela vacina, que não é, por enquanto, possível de determinar, já que a persistência de imunidade contra a varicela pode ser devida a contactos posteriores com o vírus selvagem, ainda muito prevalente na comunidade. Se a vacina actual reduzir, mas não eliminar, o vírus selvagem em circulação, e a imunidade adquirida não for de longa duração, a população adulta ficará mais susceptível e poderá verificar-se um aumento da incidência de varicela nesta faixa etária (com maior probabilidade de complicações). Apesar da efectividade a curto prazo ter sido verificada, são necessários e estão em curso estudos para monitorizar a efectividade a longo prazo.

No futuro, serão necessários mais estudos para objectivar a efectividade e impacto a longo prazo da vacinação contra a varicela, bem como aferir os factores de risco para falência vacinal e duração da imunidade vacinal.

\section{REFERÊNCIAS BIBLIOGRÁFICAS}

1. Canadian Paediatric Society, Infectious Diseases and Immunization Committee. Prevention of varicella in children and adolescents. Paediatr Child Health 2005 Sep; 10 (7): 409-412.

2. Marin M, Meissner HC, Seward JF. Varicella prevention in the United States: a review of successes and challenges. Pediatrics 2008 Sep; 122 (3): e744-51.

3. Albrecht MA. Prevention of varicella-zoster virus infection: Chickenpox. UpToDate Disponível em: www.uptodate.com [acedido em 05/11/2009].

4. Sociedade de Infecciologia Pediátrica/Sociedade Portuguesa de Pediatria. Recomendações para a vacinação contra a varicela. Acta Pediatr Port 2009 Jul-Ago; 40 (4): 185-8.

5. Bonanni P, Breuer J, Gershon A, Gershon M, Hryniewicz W, Papaevangelou $V$, et al. Varicella vaccination in Europe - taking the practical approach. BMC Med 2009 May 28; 7: 26.

6. Ebell MH, Siwek J, Weiss BD, Woolf SH, Susman J, Ewigman B, et al. Strength of Recommendation Taxonomy (SORT): a patient-centered approach to grading evidence in the medical literature. Am Fam Physician 2004 Feb 1; 69 (3): 548-56.

7. Seward JF, Marin M, Vázquez M. Varicella vaccine effectiveness in the US vaccination program: a review. J Infect Dis 2008 Mar 1; 197 Suppl 2: S82-9.

8. Marin M, Güris D, Chaves SS, Schmid S, Seward JF; Advisory Committee on Immunization Practices, Centers for Disease Control and Prevention (CDC). Prevention of varicella: recommendations of the Advisory Committee on Immunization Practices (ACIP). MMWR Recomm Rep 2007 Jun 22; 56 (RR-4): 1-40.

9. American Academy of Pediatrics Committee on Infectious Diseases. Prevention of varicella: recommendations for use of varicella vaccines in children, including a recommendation for a routine 2-dose varicella immunization schedule. Pediatrics 2007 Jul; 120 (1): 221-31.

10. Australian Government Department of Health and Ageing, Office of Health Protection. The Australian Immunization Handbook. 9th ed.; 2008. Disponível em: http://www.health.gov.au/internet/immunise/ publishing.nsf/content/handbook-home [acedido em 01/02/2012].

11. Swingler GH. Chickenpox. Clin Evid (Online) 2007 Aug 1; 2007. pii: 0912.

12. Bayer $O$, Heininger $U$, Heiligensetzer $C$, von Kries R. Metaanalysis of vaccine effectiveness in varicella outbreaks. Vaccine 2007 Sep 17; 25 (37-38): 6655-60.

13. Sheffer R, Segal D, Rahamani S, Dalal I, Linhart Y, Stein M, et al. Effectiveness of the Oka/GSK attenuated varicella vaccine for the prevention of chickenpox in clinical practice in Israel. Pediatr Infect Dis J 2005 May; 24 (5): 434-7.

14. Staat MA, Meinzen-Derr J, Welch T, Roberts NE, Jamison L, Gerber MA, et al. Varicella-related hospitalization and emergency department visit rates, before and after introduction of varicella vaccine, among white and black children in Hamilton County, Ohio. Pediatrics 2006 May; 117 (5): e833-9.

15. Lee LE, Ho H, Lorber E, Fratto J, Perkins S, Cieslak PR. Vaccine-era varicella epidemiology and vaccine effectiveness in a public elementary school population, 2002-2007. Pediatrics 2008 Jun; 121 (6): e1548-54.

16. Giammanco G, Ciriminna S, Barberi I,Titone L, Lo Giudice M, Biasio LR. Universal varicella vaccination in the Sicilian paediatric population: ra- 
pid uptake of the vaccination programme and morbidity trends over five years. Euro Surveill 2009 Sep 3; 14 (35). pii: 19321.

17. Kupek E, Tritany EF. Impact of vaccination against varicella on the reduction of the disease incidence in children and adolescents from Florianópolis, Brazil. J Pediatr (Rio J). 2009 Jul-Aug; 85 (4): 365-8.

18. Chaves SS, Haber P, Walton K, Wise RP, Izurieta HS, Schmid DS, et al. Safety of varicella vaccine after licensure in the United States: experience from reports to the vaccine adverse event reporting system, 1995-2005. J Infect Dis 2008 Mar 1;197 Suppl 2: S170-7.

19. Ferrera G, Gajdos V, Thomas S, Tran C, Fiquet A. Safety of a refrigerator-stable varicella vaccine (VARIVAX) in healthy 12- to 15-month-old children: a randomized, double-blind, cross-over study. Hum Vaccin 2009 Jul; 5 (7): 455-60.

\section{CONFLITOS DE INTERESSE}

As autoras declaram ausência de conflitos de interesses e de financiamento do estudo.

\section{ENDEREÇO PARA CORRESPONDÊNCIA}

Ana Garrido

Rua Aristides Sousa Mendes, 147

4470-232 Gueifães - Maia

E-mail: anagarridooliveira@gmail.com

Recebido em 26/04/2011

Aceite para publicação em 26/03/2012

\section{ABSTRACT}

\section{VARICELLA VACCINE IN CHILDREN}

Objectives: To review the available evidence for varicella vaccination in healthy children, analyzing its effectiveness and safety.

Data sources: MEDLINE database and evidence-based medicine websites.

Methods: A search was conducted for guidelines, systematic reviews, meta-analyses and original studies, published between January 2005 and November 2009, in English, Portuguese and Spanish, using the MeSH terms chickenpox vaccine, infant, child preschool and child. The SORT (Strength of Recommendation Taxonomy) scale of the American Family Physician was applied to evaluate the level of evidence.

Results: We found 14 studies that assessed vaccine effectiveness: 5 guidelines ( 2 with strength of recommendation A) 3 systematic reviews ( 2 with evidence level 1 ), one meta-analysis (evidence level 1), a case-control study and 4 cohort studies. Studies showed that the vaccine has an effectiveness of 70 to $90 \%$ in preventing all forms of varicella and 95 to $100 \%$ in preventing moderate to severe disease, over a period not exceeding ten years. The two-dose regimen showed greater long-term effectiveness than the single dose regimen. Two studies evaluating vaccine safety concluded that the vaccine is safe and well tolerated (one randomized controlled trial with evidence level 1 ).

Conclusion: Varicella vaccine is effective and safe in healthy children (Strength of Recommendation A). However, its implementation should be universal, to allow a high coverage rate, considering the possibility of a two-dose regimen.

Key words: Chickenpox vaccine; Infant; Child, Preschool; Child. 